\title{
Corrosion and inhibition of copper in different electrolyte solutions
}

\author{
A. Shaban ${ }^{1}$, E. Kálmán ${ }^{1, *}$, J. Telegdi ${ }^{1}$, G. Pálinkás ${ }^{1}$, Gy. Dóra ${ }^{2}$ \\ ${ }^{1}$ Central Research Institute for Chemistry HAS, H-1525 Budapest, P.O. Box 17, Hungary \\ (Fax: +36-1/325-7509, E-mail: kale@cric.chemres.hu) \\ ${ }^{2}$ Institute for Material Science, CRIP HAS, H-1121 Budapest, Konkoly Thege u. 29/33, Hungary
}

Received: 25 July 1997/Accepted: 1 October 1997

\begin{abstract}
The inhibition action of p-chlorobenzohydroxamic acid (p-Cl-BHA) and dibenzylsulphoxide (DBSO) on copper corrosion in $0.5 \mathrm{M} \mathrm{NaCl}$ at $\mathrm{pH} \approx 6.5$ and $0.1 \mathrm{M} \mathrm{Na}_{2} \mathrm{SO}_{4}$ at $\mathrm{pH} \approx 3$, respectively, were studied. The corrosion and inhibition processes were monitored by in-situ atomic force microscopy, and morphological changes on the electrode surface were registered. The p-Cl-BHA greatly enhanced the resistance of copper to pitting corrosion in an aqueous solution containing chloride ions. This effect is attributed to the formation of a continuous protective chemisorbed layer on the corroding metallic surface through which $\mathrm{Cu}_{2} \mathrm{O}$ will be stabilized. The DBSO, because of its adsorption and conversion to a more stable, less soluble sulphide compound, greatly hindered the copper corrosion in the sulphate-containing solutions.
\end{abstract}

Owing to the widespread use of copper in industrial applications, the investigation of its corrosion is of special interest. Copper has valuable properties such as high electrical and thermal conductivities and resistance to atmospheric corrosion in a natural environment. Hence, the corrosion and passivation of copper in various media have been the subject of many investigations [1-3].

The onset of localized or general corrosion in metallic materials protected by organic inhibitors is strongly linked to the stability of the inhibitor in the presence of different anions. In chloride-containing electrolytes, many inhibitor compounds are not so effective because of deterioration caused by the chloride ions.

Aromatic sulphoxides are excellent inhibitors for iron corrosion in acidic media. Several studies have dealt with the inhibition of iron corrosion in $\mathrm{H}_{2} \mathrm{SO}_{4}$ using dibenzylsulphoxide (DBSO). Trabanelli [4] and Aramaki [5] proposed that the inhibition effectiveness of DBSO is due to its conversion to

\footnotetext{
* To whom correspondence should be made.
}

a sulphide form on the surface of the electrode. Benzohydroxamic acid derivatives, such as p-chloro-benzohydroxamic acid (p-Cl-BHA), are excellent chelating agents for mono-, bi-, and trivalent metals [6], and thus they offer the possibility of inhibiting corrosion.

Besides the traditional methods used to study corrosion inhibition, an electrochemical quartz-crystal microbalance (EQCM) was used to obtain information on the behaviour of copper both in acidic and neutral media. Due to its sensitivity, the EQCM registered the mass changes of the crystal against time on a nanogram scale. Another in-situ method with high resolution that was used is atomic force microscopy (AFM). The AFM profiles a surface by measuring the inter-atomic forces between a flexible stylus and the surface of interest. The ability of AFM to image non-conductors in wet cells, organic films, etc., opens up new experimental possibilities in corrosion research, i.e. the morphology of the surface could be monitored in time by sequential imaging.

The aim of this work was to study the effect of p-Cl-BHA and DBSO on copper corrosion in chloride and sulphatecontaining solutions, respectively.

\section{Experimental procedure}

\subsection{Electrolytes}

Reagent grade chemicals and deionized water (DI) were used to prepare the following electrolytes:

$-0.1 \mathrm{M} \mathrm{Na}_{2} \mathrm{SO}_{4}$ at $\mathrm{pH} \approx 2.95$ (using $\mathrm{H}_{2} \mathrm{SO}_{4}$ )

$-0.1 \mathrm{M} \mathrm{Na}_{2} \mathrm{SO}_{4}$ at $\mathrm{pH} \approx 2.95\left(\right.$ using $\left.\mathrm{H}_{2} \mathrm{SO}_{4}\right)+5 \times 10^{-4} \mathrm{M}$ DBSO

$-0.5 \mathrm{M} \mathrm{NaCl}$ at $\mathrm{pH} \approx 6.5$ (using $\mathrm{NaOH})$

$-0.5 \mathrm{M} \mathrm{NaCl}$ at $\mathrm{pH} \approx 6.5$ (using $\mathrm{NaOH})+1 \times 10^{-3} \mathrm{M}$ pCl-BHA.

The DBSO was purified by recrystallization. The p-Cl-BHA was prepared from its appropriate carboxylic acid chloride and hydroxylamin and then purified by recrystallization. The 
purity was checked by elemental analysis and melting point determination.

\subsection{AFM measurements}

The AFM senses repulsive contact forces between a fixed flexible microcantilever and the surface of the sample. The $Z$ motion of a silicon nitride tip was monitored in height mode by mounting the sample on an $X-Y-Z$ piezoelectric tube scanner.

A Nanoscope III (Digital Instruments) EC AFM apparatus was used for studying the morphological changes. The specimen, copper disc (99.99\% purity), was polished using emery SiC paper (size 1200) and then polished further using $0.25 \mu \mathrm{m}$ diamond paste. After washing and degreasing the sample was placed into the wet cell. Using a fluid cell setup, the electrolyte was injected onto the specimen electrolytes both without and with the addition of the inhibitors under investigation. Sequential imaging of the specimen surface was performed at a number of time intervals. The images were captured and section analysis data for each sequential image was obtained. These data provided essential information on the surface morphology, i.e. on changes of the surface roughness.

\subsection{EQCM measurements}

EQCM experiments were performed using an AT-cut quartz crystal disk, with a diameter of $12 \mathrm{~mm}$ and a $10 \mathrm{MHz}$ nominal frequency. Copper was deposited from an acidic copper bath [7]. An electrochemical nanobalance system, model EQCN-701, connected to a potentiostat, model PS-205 (Elchema, NY), was used to deposit the copper layers and monitor the electrode mass.

Measurements in the acidic media were performed in three intervals. In the first interval the crystal was treated with the blank $0.1 \mathrm{M} \mathrm{Na}_{2} \mathrm{SO}_{4}$ solution; in the second interval the solution was replaced by a DBSO-inhibitor-containing electrolyte; and finally in the third interval the solution was changed back to the same aggressive solution as used in interval one. The sensitivity of the crystal was determined during copper deposition using Sauerbrey's equation [8]. Data on the change in mass or frequency were registered over a period of time.

\section{Results and discussion}

\subsection{AFM results}

The AFM measurements produced a series of images after different contact times. The images are represented in threedimensional format and in section-analysis format. Rootmean-square (RMS) values, which represent the surface roughness, were obtained from the section analysis results.

2.1.1 Copper in $0.1 \mathrm{M} \mathrm{Na}_{2} \mathrm{SO}_{4}$ and DBSO. The morphological investigations of copper electrode in $0.1 \mathrm{M} \mathrm{Na}_{2} \mathrm{SO}_{4}$ in the absence and presence of DBSO are shown in Figs. 1 and 2. The images taken in the absence of inhibitor show the corrosion process taking place along some sub-grain boundaries
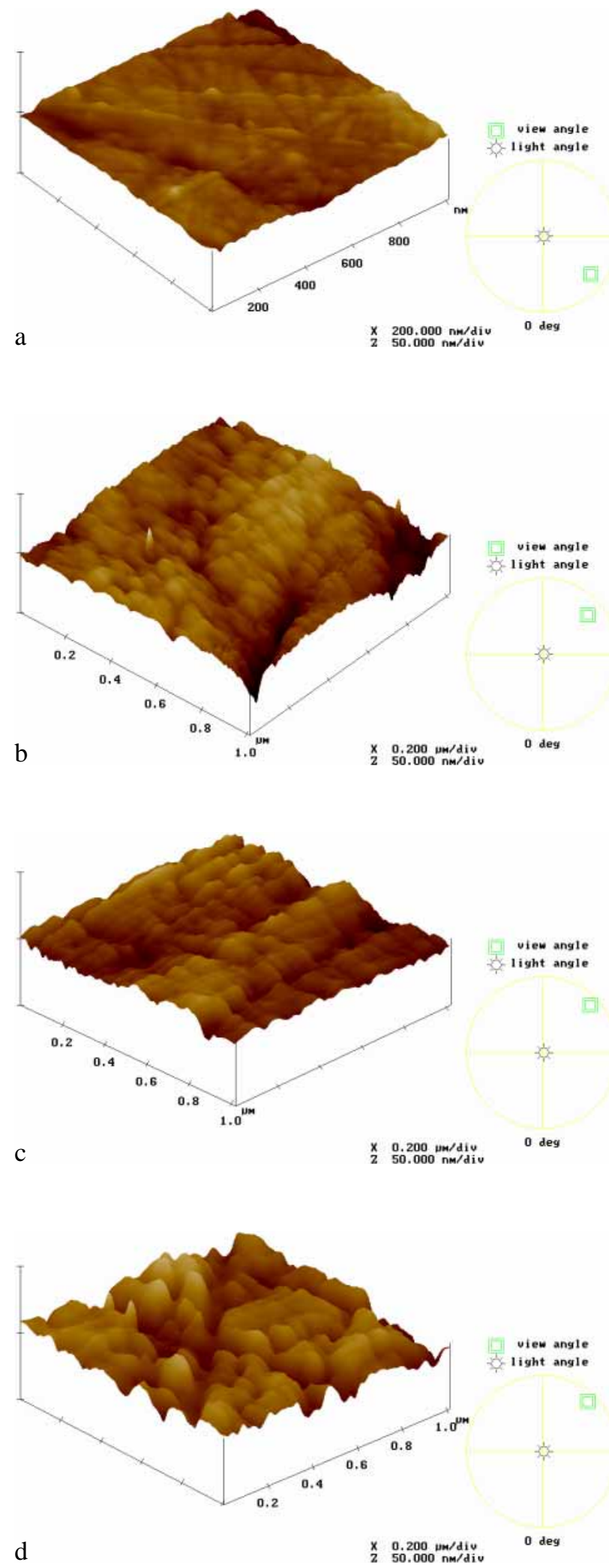

Fig. 1a-d. Morphological changes of copper in solution of $0.1 \mathrm{M} \mathrm{Na}_{2} \mathrm{SO}_{4}$, at $\mathrm{pH}=2.95$; at different times; scan size: $X Y: 1 \mu \mathrm{m} ; Z: 50 \mathrm{~nm} / \mathrm{div}$; at room temperature. a $t=0 ; \mathbf{b}=15 \mathrm{~min} ; \mathbf{c} t=30 \mathrm{~min} ; \mathbf{d} t=45 \mathrm{~min}$

(Fig. 1). The surfaces became rougher during the time period due to the dissolution of the copper, as shown by the RMS values. In the presence of DBSO the surface was not severely 

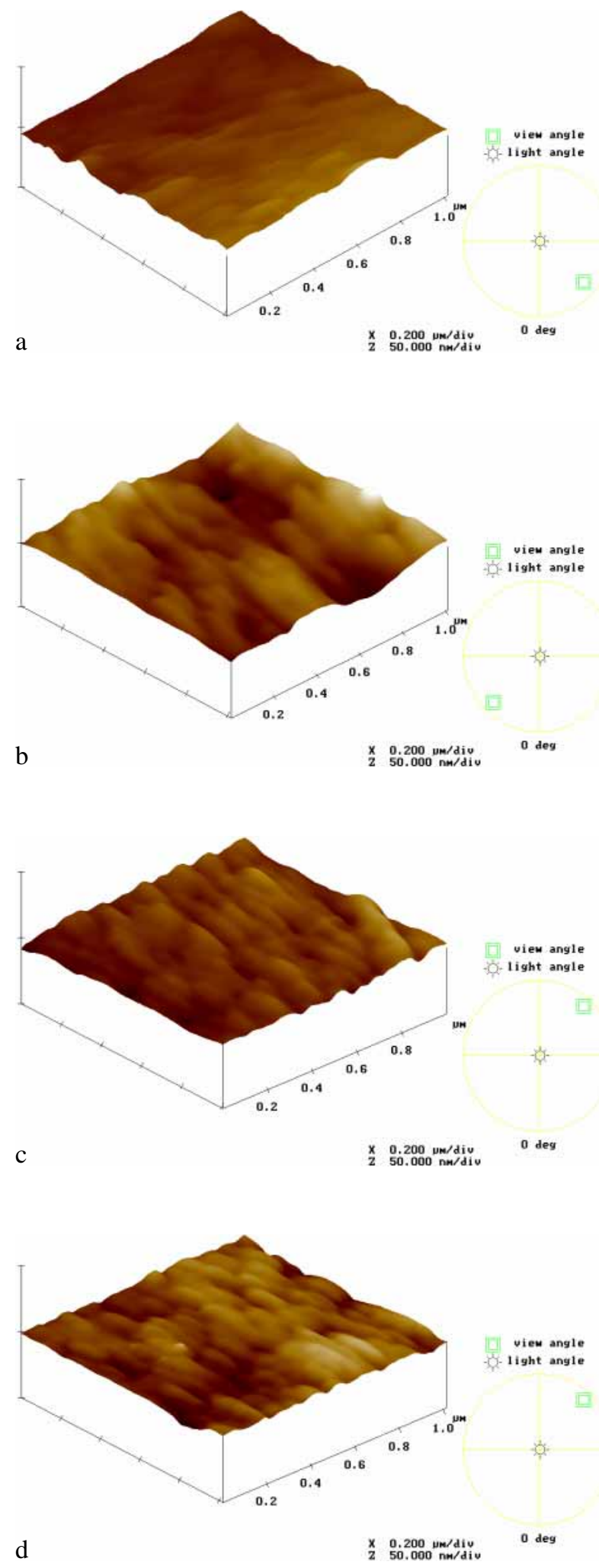

Fig. 2a-d. Morphological changes of copper in solution of $0.1 \mathrm{M} \mathrm{Na}_{2} \mathrm{SO}_{4}$ and $0.5 \mathrm{mM}$ DBSO at $\mathrm{pH}=2.95$; at different times; scan size: $X Y: 1 \mu \mathrm{m}$; $Z: 50 \mathrm{~nm} / \mathrm{div}$; at room temperature. a $t=0 \mathrm{~min} ; \mathbf{b} t=15 \mathrm{~min} ; \mathbf{c} t=30 \mathrm{~min}$; d $t=45 \mathrm{~min}$

damaged by corrosion and a smoother surface was developed because of the effects of the inhibitor. The RMS values for the surfaces with and without the presence of the inhibitor
Table 1. RMS values from the AFM sequential images of copper in different solutions, in the absence and presence of inhibitors

\begin{tabular}{ccccc}
\hline \multicolumn{5}{c}{ RMS nm } \\
Solution & $0.1 \mathrm{M} \mathrm{Na}_{2} \mathrm{SO}_{4}$ & $\begin{array}{c}0.1 \mathrm{M} \mathrm{Na}_{2} \mathrm{SO}_{4} \\
+\mathrm{DBSO}\end{array}$ & $0.5 \mathrm{M} \mathrm{NaCl}$ & $\begin{array}{c}0.5 \mathrm{M} \mathrm{NaCl}+ \\
\mathrm{p}-\mathrm{Cl}-\mathrm{BHA}\end{array}$ \\
\hline Time (min) & & & 3.3 & 7.2 \\
0 & 1.7 & 1.8 & 14.7 & 7.3 \\
15 & 2.5 & 2.5 & 19.4 & 1.4 \\
30 & 4.7 & 2.1 & 23.9 & 1.3 \\
45 & 7.5 & 2.1 & & \\
\hline
\end{tabular}

are tabulated in Table 1. In the presence of DBSO, an almost insoluble thin layer started to form on the electrode surface. This layer, consisting of the inhibitor and some corrosion products, isolated the electrode surface, accounting for the inhibition effect. The corrosion was largely decreased by plugging the active sites on the surface. The action of DBSO on copper corrosion is a result of the conversion of the sulphoxide to a less soluble sulphide (DBS) on the surface [5].

2.1.2 Copper in $0.5 \mathrm{M} \mathrm{NaCl}$ and p-Cl- BHA. The images of the copper electrode surface in the absence and presence of p-Cl-BHA are shown in Figs. 3 and 4. In the absence of the inhibitor the pit formation and growth, as a localized form of copper corrosion in the chloride containing media, was demonstrated, as shown in Fig. 3. As time proceeded, the pits grew in size and depth and corrosion products started to accumulate on the surface. The RMS values of the images increased in time as the roughness increased. On the contrary, the addition of p-Cl-BHA obviously hindered the localized attack on the copper surface (Fig. 4). The RMS values were decreased, indicating a smoothing of the surface. The corrosion products seen in the absence of the inhibitor were not present. Thus a stable complex was formed through the sorption of the inhibitor on the corroding surface and this hindered the further dissolution of the metal.

\subsection{EQCM results}

The EQCM results are shown in terms of frequency or mass changes of the crystal as a function of time. The corrosion rate of copper in different solutions could be evaluated as the slope of the curve at any particular point.

2.2.1 Copper in $0.1 \mathrm{M} \mathrm{Na}_{2} \mathrm{SO}_{4}$ and DBSO. The EQCM results of copper in $0.1 \mathrm{M} \mathrm{Na}_{2} \mathrm{SO}_{4}$ with the addition of DBSO are shown in Fig. 5. It could be seen that DBSO sharply reduced the slope of the frequency change. A decrease in the rate of change of the frequency indicates a decrease in the metal dissolution rate. The inhibition effect of DBSO persisted even in the absence of the inhibitor (interval 3) which indicates the strong adsorption of DBSO on the surface. The thickness reduction rate for copper in $0.1 \mathrm{M} \mathrm{Na}_{2} \mathrm{SO}_{4}$ in the presence of DBSO was $152 \mu \mathrm{m} /$ year comparing to $710 \mu \mathrm{m} /$ year for the blank solution, which gives an $80 \%$ inhibition efficiency. 

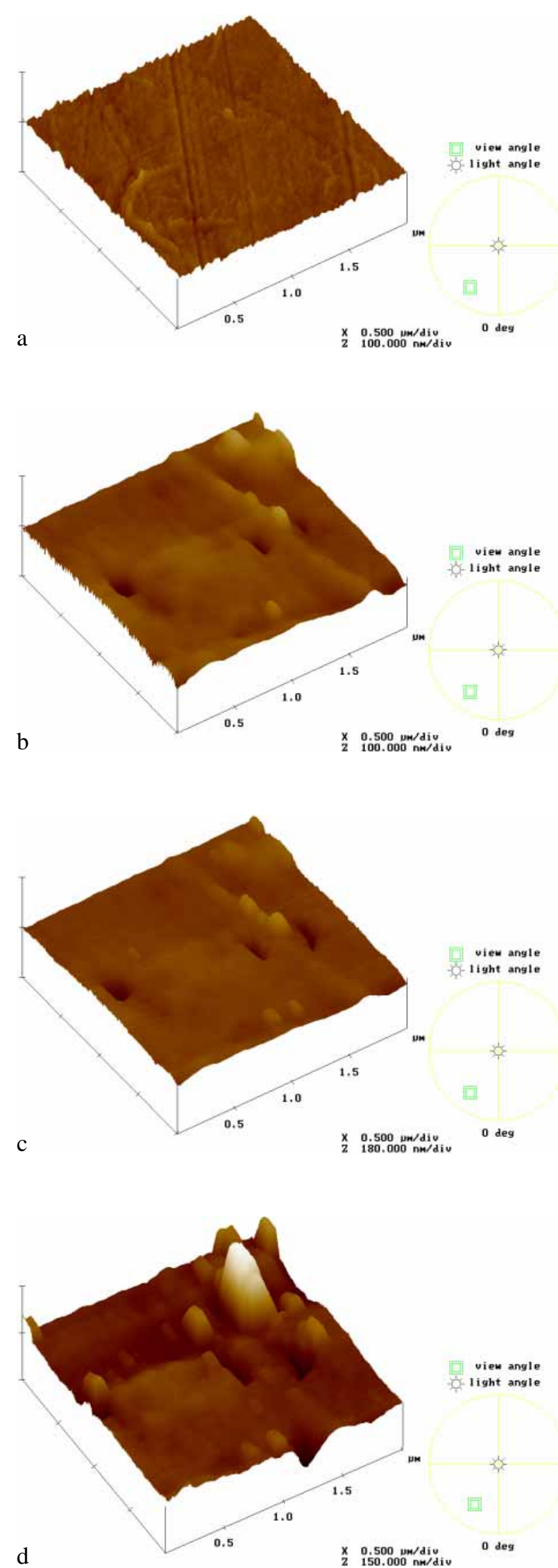

Fig. 3a-d. Morphological changes of copper in solution of $0.1 \mathrm{M} \mathrm{NaCl}$, at $\mathrm{pH}=6.5$; at different times; scan size: $X Y: 1 \mu \mathrm{m} ; Z: 50 \mathrm{~nm} /$ div.; at room temperature. a $t=0 \mathrm{~min} ; \mathbf{b} t=15 \mathrm{~min} ; \mathbf{c} t=30 \mathrm{~min} ; \mathbf{d} t=45 \mathrm{~min}$
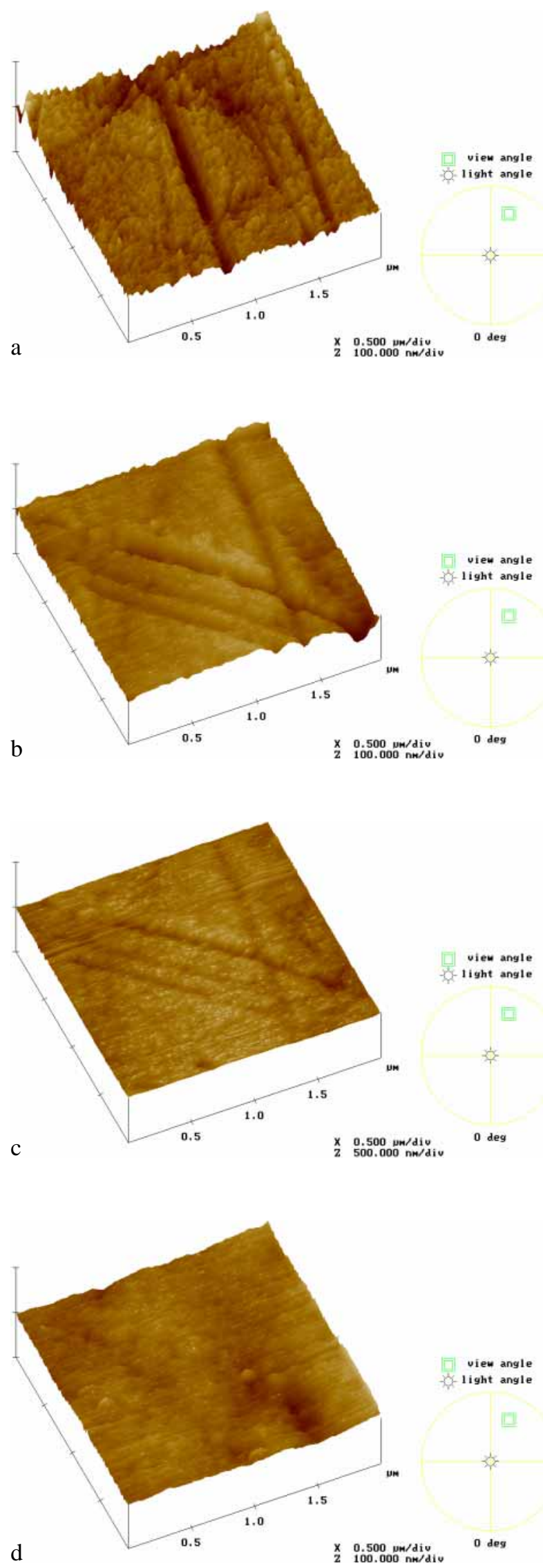

Fig. 4a-d. Morphological changes of copper in $0.1 \mathrm{M} \mathrm{NaCl}+$ p-Cl-BHA, at $\mathrm{pH}=6.5$; at different times; scan size: $X Y: 1 \mu \mathrm{m} ; Z: 50 \mathrm{~nm} /$ div.; at room temperature. a $t=0 \mathrm{~min} ; \mathbf{b} t=15 \mathrm{~min} ; \mathbf{c} t=30 \mathrm{~min} ; \mathbf{d} t=45 \mathrm{~min}$ 


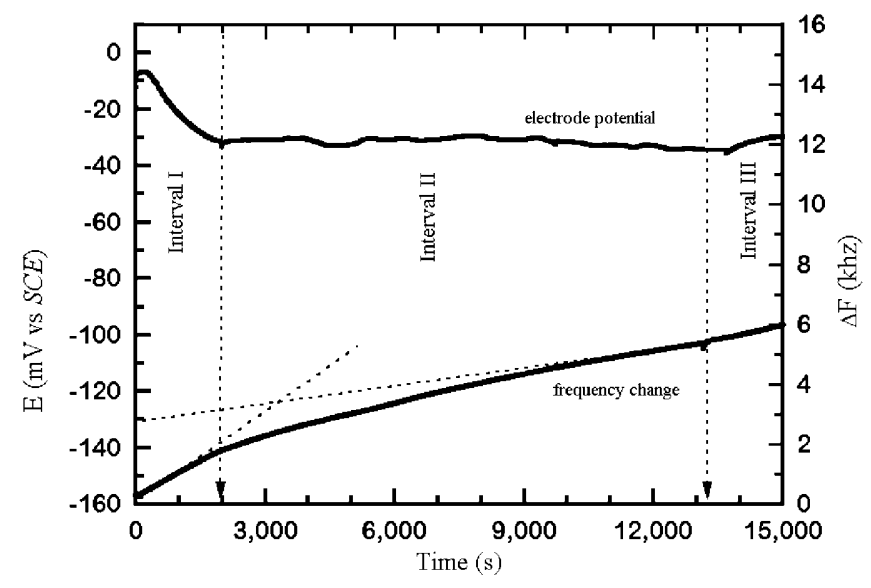

Fig. 5. EQCM results for copper in $0.1 \mathrm{M} \mathrm{Na}_{2} \mathrm{SO}_{4}+\mathrm{DBSO}$, at $\mathrm{pH}=2.95$

2.2.2 Copper in $0.5 \mathrm{M} \mathrm{NaCl}$ and p- Cl- BHA. The p-Cl-BHA clearly reduced the copper dissolution rate in $0.5 \mathrm{M} \mathrm{NaCl}$ solution, as shown in Fig. 6. The mass of the electrode increased due to the adsorption of the inhibitor and the formation of an inhibitor-corrosion-products complex on the electrode surface during the process. This protective film accounts for the inhibition efficiency of p-Cl-BHA against the localized attack on the copper electrode in $\mathrm{NaCl}$.

\section{Conclusions}

In summary, by means of high-resolution AFM and EQCM, unambiguous evidence has been provided to show the corrosion inhibition actions of DBSO and of p-Cl-BHA on copper, in $0.1 \mathrm{M} \mathrm{Na}_{2} \mathrm{SO}_{4}$ and $0.5 \mathrm{M} \mathrm{NaCl}$ solutions, respectively. AFM demonstrated its ability to be applied as a highly sensi-

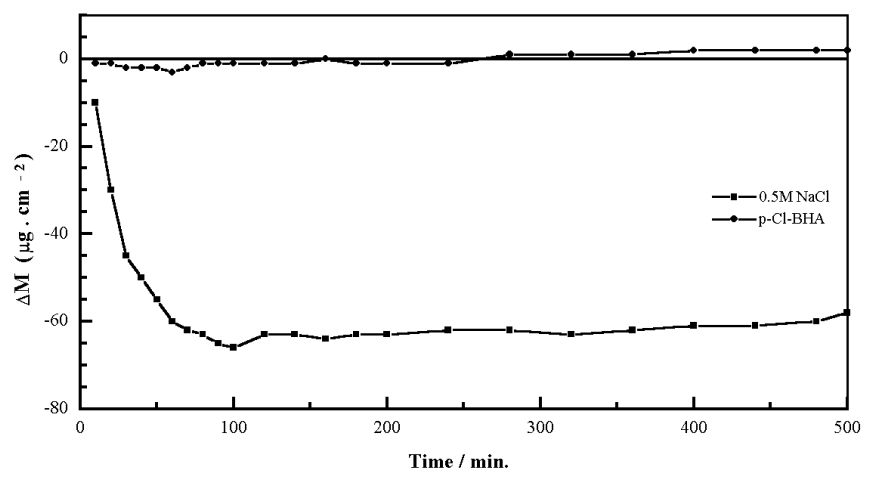

Fig. 6. EQCM results for copper in $0.1 \mathrm{M} \mathrm{NaCl}+\mathrm{p}-\mathrm{Cl}-\mathrm{BHA}$, at $\mathrm{pH}=6.5$

tive in-situ technique in order to monitor and register the processes taking place during corrosion and inhibition. DBSO effectively inhibited copper corrosion in acidic media by converting it to a more insoluble DBS. The p-Cl-BHA formed a stable film on the surface that provided excellent protection against corrosion.

\section{References}

1. L. Kiss: Kinetics of Electrochemical Metal Dissolution (Elsevier, Amsterdam, 1988)

2. H.P. Lee, K. Nobe: J. Electrochem. Soc. 137, 2035 (1986)

3. F.K. Crundwell: Electrochim. Acta 37, 2707 (1992)

4. G. Trabanelli: Corrosion'89, New Orleans, 133 (1989)

5. N. Ohno, J. Uehara, K. Aramaki: J. Electrochem. Soc. 140, 2512 (1993)

6. B. Kurzak, W. Bal, H. Kozlowski: J. Inorg. Biochem. 38, 9 (1990)

7. E. Müller: Praktikum der Electrochemie (Kopp Verlag, Rottenburg 1953)

8. G. Sauerbrey: Z. Phys. 155, 206 (1959) 